\title{
Maternal BRG1 regulates zygotic genome activation in the mouse
}

\author{
Scott J. Bultman, ${ }^{1,3,6}$ Thomas C. Gebuhr, ${ }^{1,3,4}$ Hua Pan, ${ }^{2}$ Petr Svoboda, ${ }^{2,5}$ Richard M. Schultz, ${ }^{2}$ \\ and Terry Magnuson ${ }^{1}$ \\ ${ }^{1}$ Department of Genetics and The Carolina Center for Genome Sciences, University of North Carolina, Chapel Hill, North \\ Carolina 27599, USA; ${ }^{2}$ Department of Biology, University of Pennsylvania, Philadelphia, Pennsylvania 19104, USA
}

Zygotic genome activation (ZGA) is a nuclear reprogramming event that transforms the genome from transcriptional quiescence at fertilization to robust transcriptional activity shortly thereafter. The ensuing gene expression profile in the cleavage-stage embryo establishes totipotency and is required for further development. Although little is known about the molecular basis of ZGA, oocyte-derived mRNAs and proteins that alter chromatin structure are likely crucial. To test this hypothesis, we generated a maternal-effect mutation of Brg1, which encodes a catalytic subunit of SWI/SNF-related complexes, utilizing Cre-loxP gene targeting. In conditional-mutant females, BRG1-depleted oocytes completed meiosis and were fertilized. However, embryos conceived from BRG1-depleted eggs exhibited a ZGA phenotype including two-cell arrest and reduced transcription for $\sim 30 \%$ of expressed genes. Genes involved in transcription, RNA processing, and cell cycle regulation were particularly affected. The early embryonic arrest is not a consequence of a defective oocyte because depleting maternal BRG1 after oocyte development is complete by RNA interference (RNAi) also resulted in two-cell arrest. To our knowledge, Brg1 is the first gene required for ZGA in mammals. Depletion of maternal BRG1 did not affect global levels of histone acetylation, whereas dimethyl-H3K4 levels were reduced. These data provide a framework for understanding the mechanism of ZGA.

[Keywords: Two-cell embryo; BRG1; SWI/SNF; maternal-effect mutation; transcriptional regulation; zygotic genome activation]

Supplemental material is available at http://www.genesdev.org.

Received March 28, 2006; revised version accepted April 26, 2006.

In Drosophila and Xenopus, mRNAs stockpiled in the oocyte are stable after fertilization and regulate many aspects of embryonic development (Wolpert et al. 2002). Conversely, in mammals, oocyte-derived mRNAs are degraded shortly after fertilization and cannot direct more than the first few cell divisions (Thompson et al. 1998). Therefore, zygotic genome activation (ZGA) must occur very early during mammalian development. In the mouse, a minor burst of ZGA toward the end of the one-cell stage is followed by a major burst during the two-cell stage (Latham et al. 1992; Vernet et al. 1992; Aoki et al. 1997; Thompson et al. 1998; Schultz 2002). In a variety of other mammals, including humans, the embryonic genome is activated in a similar stepwise manner at the four- to eight-cell stage or the eight- to 16-cell stage (Telford et al. 1990; Kanka 2003). ZGA is required

\footnotetext{
${ }^{3}$ These authors contributed equally to this work.

Present addresses: ${ }^{4}$ Novartis Institutes for Biomedical Research, Cambridge, MA 02139, USA; ${ }^{5}$ Friedrich Miescher Institute for Biomedical Research, Maulbeerstrasse 66, 4058 Basel, Switzerland.

${ }^{6}$ Corresponding author.

E-MAIL scott_bultman@med.unc.edu; FAX (919) 843-4682.

Article is online at http://www.genesdev.org/cgi/doi/10.1101/gad.1435106.
}

for continued development because mRNAs common to the oocyte and embryo (e.g., genes involved in the maternal-to-zygotic transition and housekeeping genes) are replenished and many genes not transcribed in the oocyte are expressed for the first time. The outcome of ZGA is a novel gene expression profile that establishes the totipotent state of each blastomere in the cleavagestage embryo. This step is a prerequisite for future cell lineage commitments and differentiation events that underlie pattern formation and organogenesis.

Changes in chromatin structure are thought to play an important role in reprogramming gene expression during ZGA (Schultz and Worrad 1995; Thompson et al. 1998; Kanka 2003). For example, an apparent increase in histone acetylation accompanies the one-to-two-cell transition in the mouse (Worrad et al. 1995; Stein et al. 1997; Sarmento et al. 2004). However, it remains unclear whether this epigenetic modification is a causative factor or is merely consequential to acquisition of transcriptional competence. Indeed, very little is known about the molecular basis of ZGA because mutations that perturb the process have yet to be identified. One potential problem may be that genetic redundancy has prevented 
the appearance of ZGA phenotypes. For instance, there are more than a dozen histone acetyltransferases (HATs) that modify many of the same amino acids. Another potential problem is that maternally derived proteins, which are synthesized in the oocyte and regulate ZGA, are not perturbed by conventional mutagenesis strategies. When an intercross is performed, maternally derived proteins could potentially support development to implantation (perhaps explaining why null mutations rarely, if ever, result in early cleavage-stage lethality) (http://www.informatics.jax.org). If the mutation confers homozygous lethality, then mutant females cannot be recovered and bred to evaluate the role of the maternal factor in the early embryo.

Mammalian SWI/SNF-related chromatin remodeling complexes regulate transcription and are good candidates for being involved in ZGA. They have a molecular mass of $\sim 1 \mathrm{MDa}$ and consist of approximately nine subunits, although their composition can vary in different cell types and tissues (Wang et al. 1996a,b; Kingston and Narlikar 1999; Olave et al. 2002; Smith et al. 2003; Mohrmann and Verrijzer 2005). None of these complexes bind to DNA in a sequence-specific manner but rather are recruited to promoters of target genes by sequencespecific transcription factors (Peterson and Workman 2000; Bultman et al. 2005). Once recruited, the BRG1 catalytic subunit exhibits DNA-dependent ATPase activity, and the energy derived from ATP hydrolysis alters the conformation and position of nucleosomes (Kingston and Narlikar 1999). DNA-histone contacts are broken, and histone octamers can be slid several hundred base pairs upstream or downstream (Bazett-Jones et al. 1999; Whitehouse et al. 1999). As a result of this nucleosome disruption activity, promoters are made accessible to the RNA polymerase II holoenzyme so transcription can be initiated.

We previously demonstrated that Brg1 is essential in the mouse as null homozygotes die at the blastocyst stage (Bultman et al. 2000). Several other subunits of SWI/SNF-related complexes, often referred to as BRG1associated factors (BAFs), have also been knocked out and confer peri-implantation lethality as well (Klochendler-Yeivin et al. 2000; Roberts et al. 2000; Guidi et al. 2001; Kim et al. 2001; Lickert et al. 2004; Wang et al. 2004). However, Brg1 might be required before the blastocyst stage because it is expressed in oocytes (LeGouy et al. 1998; Bultman et al. 2000), and maternally derived BRG1 protein, stockpiled in oocytes of heterozygous females, may mask an even earlier phenotype in null homozygotes.

Here, we describe an oocyte-specific Brg1 mutation generated by Cre-loxP gene targeting. In conditional mutant females, BRG1-depleted oocytes are meiotically competent and capable of being fertilized, but embryos conceived from depleted eggs exhibit a ZGA defect. Development of these embryos is arrested at the two- to four-cell stage, and transcriptional activity is reduced for $\sim 30 \%$ of genes expressed at this stage, with genes involved in transcription, RNA processing, and cell cycle regulation being particularly affected. The cleavage-stage arrest is not simply a consequence of a defective oocyte because depletion of maternal BRG1 subsequent to normal oocyte development (through RNA interference [RNAi]) also results in two- to four-cell arrest. Rather, examination of covalent histone modifications in maternally depleted embryos implicate a role for maternal BRG1 in establishing chromatin structure and transcriptional competence at the two-cell stage.

\section{Results}

Reduced fertility of Brg1 ${ }^{\text {Zp3-Cre }}$ conditional mutant females

To generate an oocyte-specific Brg1 mutation, we crossed previously described knockout and transgenic mouse stocks (Lewandoski et al. 1997; Sumi-Ichinose et al. 1997; Bultman et al. 2000). The resulting $B r g 1^{\text {Zp3-Cre }}$ stock had a genotype of Brg1 $1^{\text {null/floxed }}$, $\mathrm{Tg}^{\text {Zp3-Cre }}$. Brg $^{\text {nulll/floxed }}$ mice have a null allele (Brg1 $\left.{ }^{\text {null }}\right)$ balanced with a functionally normal floxed allele $\left(\right.$ Brg $\left.^{\text {floxed }}\right)$ that is converted to a recombined null allele (Brg1 $\left.1^{\text {tfloxed }}\right)$ in cells expressing Cre (Gebuhr et al. 2003). The zona pellucida 3-Cre transgene $\left(\mathrm{Tg}^{\mathrm{Zp} 3-\mathrm{Cre}}\right)$ is expressed only in oocytes and contained a nuclear localization signal (NLS) to increase the efficiency of Cre-mediated recombination (Lewandoski et al. 1997). Therefore, $B r g 1^{\text {Zp3-Cre }}$ conditional mutant females were heterozygous for the Brg1-null mutation in all tissues except the germline, which had a homozygous null genotype.

$B r g 1^{\text {Zp3-Cre }}$ females were bred to wild-type males to test their fertility. Both the number of litters born and litter sizes were markedly reduced compared with control females having either a wild-type or heterozygous germline (Table 1). To investigate a potential defect in female germ cell development, we analyzed hematoxylin and eosin $(\mathrm{H} \& \mathrm{E})$-stained sections of ovaries from control and conditional mutant females. We identified primary follicles, secondary follicles, and corpora lutea in both genotypic classes and did not observe any histological defects in conditional mutant ovary sections (Fig. 1A,B). In addition, we recovered a normal number of unfertilized eggs from superovulated, unmated $B r g 1^{Z p 3-C r e}$ females (Fig. 1C). Both the size and morphology (including extrusion of the first polar body and metaphase II arrest) of these mutant eggs was similar to controls (Fig. 1D).

Table 1. Reduced fertility of Brg1 $1^{\text {Zp3-Cre }}$ conditional mutant females

\begin{tabular}{lccc}
\hline $\begin{array}{l}\text { Germline } \\
\text { genotype }^{\mathrm{a}}\end{array}$ & $\begin{array}{c}\text { Number of } \\
\text { females }\end{array}$ & $\begin{array}{c}\text { Mean number } \\
\text { of litters }\end{array}$ & $\begin{array}{c}\text { Mean number } \\
\text { of pups } \\
\text { per litter }\end{array}$ \\
\hline$+/+$ & 5 & $5.8 \pm 0.3$ & $9.8 \pm 2.9$ \\
$+/-$ & 5 & $5.3 \pm 0.5$ & $6.5 \pm 2.5$ \\
$-/-$ & 6 & $1.3 \pm 0.3$ & $1.5 \pm 0.3$ \\
\hline$\left.{ }^{a}+/++\right)$ Brg1//floxed & no transgene; (+/-) Brg1//floxed with Zp3-Cre \\
transgene; (-/-) Brg1 ${ }^{\text {null/floxed }}$ with Zp3-Cre transgene. \\
bated with wild-type males over a 4-mo period.
\end{tabular}


Figure 1. Analysis of $B r g 1^{\text {Zp3-Cre }}$ mutant germline. $(A, B) \mathrm{H} \&$ E-stained ovary sections from wild-type control $(A)$ and conditional mutant $(B)$ females at $100 \times$ magnification. Primary follicles (arrowheads), secondary follicles (arrows) follicles, and corpora lutea $\left({ }^{\star}\right)$ are indicated. $(C)$ Average number of unfertilized eggs recovered from superovulated wild-type control (C) and conditional mutant $(\mathrm{M})$ females. (D) DIC (top) and DAPI (bottom) images of wild-type control $(\mathrm{C})$ and conditional mutant (M) ovulated eggs at $400 \times$ magnification. Polar bodies and MII-arrested chromosomes are visible in DIC and DAPI images, respectively. $(E, F) B r g 1$ gene product is depleted in unfertilized eggs from conditional mutant females. $(E)$ Image of ethidium bromide stained agarose gel containing $\beta$-actin (1020 base pairs [bp]) and Brg1 (585 bp) RT-PCR products. (MW) Onekilobase ladder molecular-weight standard; (+) positive control consisting of wild-type neonatal tissues; (-), negative control consisting of wild-type neonatal tissues except reverse transcriptase was omitted from RT reaction; (C) 20 unfertilized eggs from wild-type control; (M) 20 unfertilized eggs from conditional mutant. (F) IF of BRG1 protein in unfertilized eggs from wildtype control (C) or conditional mutant (M) females. DIC
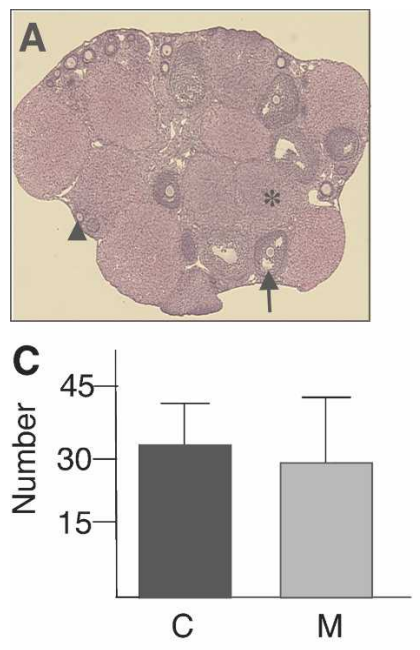

E

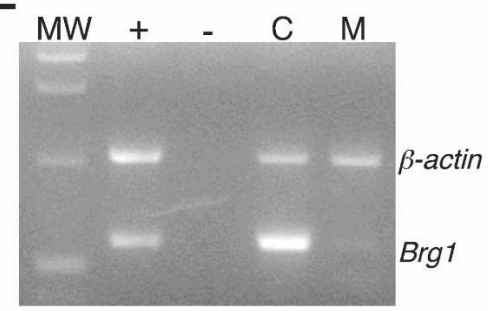

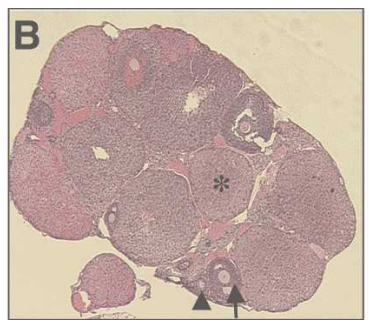

D

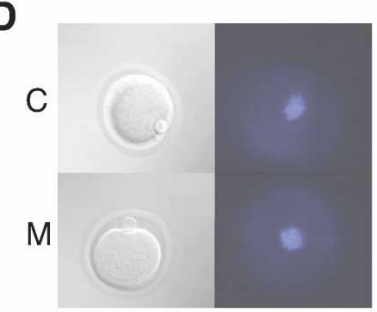

$\mathbf{F}$

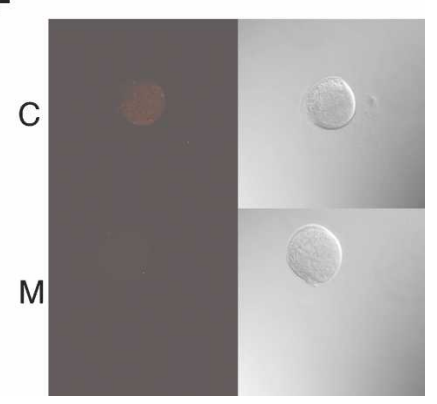

\section{Characterization of Cre-mediated recombination}

PCR genotyping was performed to evaluate the specificity and efficiency of Cre-mediated recombination at the Brg1 locus. The floxed allele was amplified from tail samples, whereas the $\Delta$ floxed allele could not be detected (Supplementary Fig. S1). These results were anticipated because the Zp3-Cre transgene is not expressed in somatic tissues (Lewandoski et al. 1997). Also as expected, the floxed allele was amplified in eggs from control mice lacking a Zp3-Cre transgene, whereas the $\Delta$ floxed allele was amplified in eggs from $\operatorname{Brg} 1^{\text {Zp3-Cre }}$ females carrying the Zp3-Cre transgene (Supplementary Fig. S1). Brg1+/floxed, $\mathrm{Tg}^{\mathrm{Zp3} \text {-Cre }}$ carrier females were bred to wild-type males and transmitted the $\Delta$ floxed allele but not the floxed allele to 17 progeny (Supplementary Fig. S1; data not shown), indicating that Cre-mediated recombination was highly efficient.

The timing of recombination in the female germline is also a potentially important factor because Brg1 is expressed at the same time as $\mathrm{Zp} 3$-Cre during the oocyte growth phase (Pan et al. 2005). Considering that Brg1 transcription might have occurred in the oocyte prior to the floxed-to- $\Delta$ floxed recombination event, we analyzed Brg1 expression in ovulated, unfertilized eggs. We performed RT-PCR and detected Brg1 mRNA at robust levels in controls but only low levels in mutants (Fig. 1E). Moreover, BRG1 protein was readily detected by immunofluorescence (IF) in controls but not mutants (Fig. 1F). These results confirm that Brg1 gene product was significantly depleted in mutant oocytes.
Cleavage-stage arrest of Brg1 $1^{\text {Zp3-Cre maternally }}$ depleted embryos

To investigate whether the reduced reproductive performance of $B r g 1^{Z p 3-C r e}$ females might be explained by an embryonic phenotype, we bred $B r g 1^{\text {Zp3-Cre }}$ and control females to wild-type males and flushed two-cell embryos out of oviducts on embryonic day 1.5 (E1.5). Brg1 $1^{\text {Zp3-Cre }}$ females produced two-cell embryos that appeared normal (Fig. 2A,E), indicating that maternal Brg1 is not required for any aspect of oogenesis, including oocyte growth, meiosis I, fertilization, or meiosis II. However, embryo culture experiments revealed very few maternally depleted embryos from $B r g 1^{Z p 3-C r e}$ females that developed to the blastocyst stage (Fig. 2A-D), whereas nearly all of the embryos from control females did so (Fig. 2E-H). The vast majority $(88 \%)$ of maternally depleted embryos were arrested in the early cleavage stages, with $78 \%$ arresting at the two-cell stage and $10 \%$ at the three- or four-cell stage (Fig. 2I). In contrast, only $3 \%$ of embryos from control females were arrested at these cleavage stages (Fig. 2I).

The relevant genetic difference between the two classes of embryos cultured in Figure 2, A- D compared with Figure 2, E-H, was the genotype of their mothers' germlines (i.e., maternal genotype). Maternally depleted embryos had a maternal genotype of $\mathrm{Brg}^{-/-}$and a zygotic genotype of $\mathrm{Brg}^{+/-}$, whereas controls had a maternal genotype of $\mathrm{Brg}^{+/-}$and a zygotic genotype of either $\mathrm{Brg}^{+/+}$or $\mathrm{Brg}^{+/-}$(there was no phenotypic difference between these two control subclasses). 

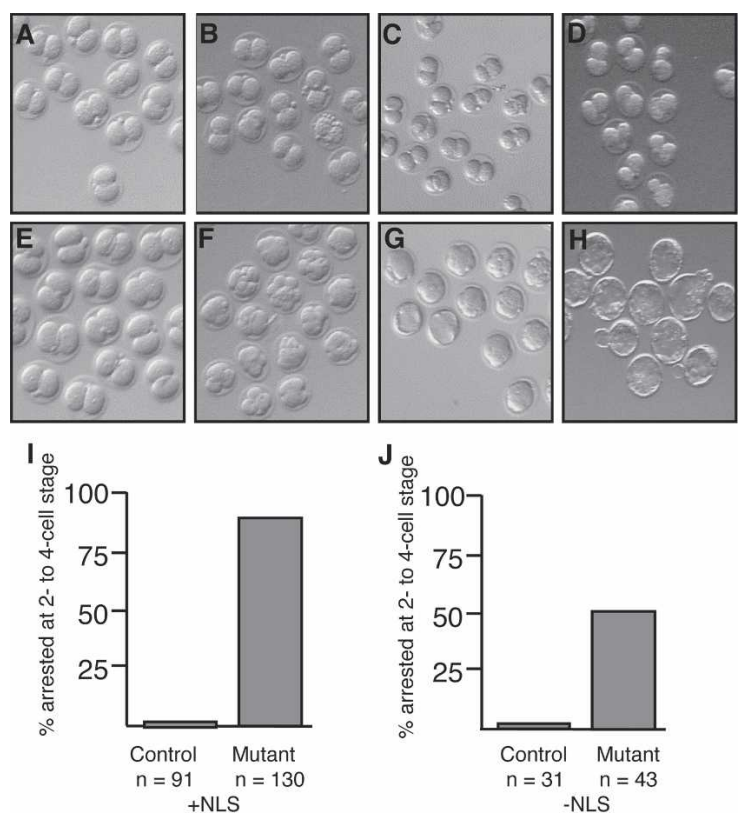

Figure 2. Cleavage-stage arrest of $B r g 1^{\text {Zp3-Cre }}$ maternally depleted embryos. $(A-H)$ Representative bright-field photographs from an embryo culture experiment. Maternally depleted $(A)$ and control $(E)$ embryos were flushed out of oviducts at the two-cell stage on E1.5. Maternally depleted $(A-D)$ and control $(E-H)$ embryos were subsequently cultured for $1 \mathrm{~d}$ (equivalent of E2.5) $(B, F), 2 \mathrm{~d}$ (equivalent of E3.5) $(C, G)$, or $3 \mathrm{~d}$ (equivalent of E4.5) $(D, H)$. Maternally depleted embryos remained at the twocell stage throughout the culture period $(B-D)$. Control embryos advanced to the uncompacted and compacted morula stages $(F)$, compacted morula and blastocyst stages $(G)$, and expanded blastocyst stage $(H)$. Embryos came from control $\left(B r g 1^{+/ f l o x e d}\right.$, $\mathrm{Tg}^{\text {Zp3-Cre }} \mid$ or Brg1 $1^{\text {Zp3-Cre }}$ females bred to wild-type males. (I) Quantification of the two- to four-cell arrest in control (C) and maternally depleted (M) embryos after the 3-d culture period. Numbers of embryos cultured are indicated. $(J)$ Quantification of the two- to four-cell arrest in embryos with a $\mathrm{Zp3}$ Cre transgene lacking a NLS after 3-d culture period. Numbers of embryos cultured are indicated.

Therefore, $B r g 1^{Z p 3-C r e}$ is clearly a maternal-effect mutation.

In our initial embryo culture experiments, as described above, $12 \%$ of the maternally depleted embryos did not arrest at the two- to four-cell stage but advanced to the blastocyst stage. The timing of the floxed-to- $\Delta$ floxed recombination event might explain the presence of these "escapers." Zp3-Cre and Brg1 are both transcribed during the oocyte growth phase (Pan et al. 2005). Therefore, Cre must be transcribed and translated, enter the nucleus, and mediate recombination of the Brg1 floxed allele before $\operatorname{Brg} 1$ mRNA reaches appreciable levels. It was our hypothesis that enough Brg1 gene product is synthesized to be functional in $12 \%$ of mutant oocytes. To test this hypothesis, we repeated the embryo culture experiments with a second $B r g 1^{Z p 3-C r e}$ stock lacking a NLS in the transgene (de Vries et al. 2000). The prediction was that, without a NLS, Cre would not enter the nucleus as efficiently, recombination would occur later during oocyte development, maternal Brg1 mRNA levels would surpass a critical threshold in a higher percentage of eggs, and more embryos would escape the two-cell arrest. This prediction proved correct as $\sim 50 \%$ of embryos escaped the developmental arrest (Fig. 2J). Consequently, all subsequent experiments were performed with the $B r g 1^{Z p 3-C r e}$ stock containing the NLS since it conferred a more highly penetrant phenotype.

\section{Reduced transcription in maternally depleted embryos}

Considering that $B r g 1^{\text {Zp3-Cre }}$ females were bred to wildtype males, all of the maternally depleted embryos had a heterozygous genotype. To evaluate zygotic expression of the wild-type paternal allele, which is normally expressed at the two-cell stage based on transcript-profiling experiments (Zeng et al. 2004), we performed RT-PCR on two-cell embryos. Brg1 mRNA was detected at robust levels in control embryos but not detected in maternally depleted embryos (Fig. 3A). This result suggests maternal mRNA is degraded and replaced by zygotic transcripts in control embryos but not maternally depleted embryos. On the one hand, maternal BRG1 may regulate zygotic Brg1 expression via an autoregulatory mechanism. On the other hand, maternal BRG1 may not only regulate zygotic Brg1 transcription but also regulate the transcription of other genes as part of ZGA. The observed cleavage-stage arrest is consistent with a ZGA defect because blocking embryonic transcription with $\alpha$-amanitin does not prevent the one-to-two-cell transition but does inhibit progression to the four-cell stage (Flach et al. 1982; Bolton et al. 1984; Schultz 1993).

The transcription-requiring complex (TRC) is an accepted marker for ZGA (Schultz 1993). Therefore, we analyzed TRC synthesis and observed a marked reduction in maternally depleted embryos compared with control embryos (Fig. 3B). The expression of Spindlin (SPIN), which is synthesized from maternal transcripts (Oh et al. 1997), was relatively unaffected and suggests that the overall reduction in TRC synthesis was unlikely the result of reduced metabolism or poor viability.

Reduced levels of TRC synthesis suggested that the major reprogramming of gene expression that occurs during the two-cell stage did not occur properly in maternally depleted embryos (i.e., genes that are normally activated during this transition were not fully activated). Consistent with this proposal, a cluster dendrogram revealed that maternally depleted and control two-cell embryos clustered separately (Supplementary Fig. S2), and microarray analysis revealed 315 out of $\sim 1000 \alpha$-amanitin-sensitive genes (Zeng and Schultz 2005) were downregulated by at least twofold in maternally depleted embryos compared with controls (Supplementary Table S1). This finding indicates that maternal BRG1 is a significant transcriptional regulator during $\mathrm{ZGA}_{\text {; }}$ at the same time, however, BRG1 is not part of the core transcriptional machinery since only a subset of genes are affected. To validate the transcript profiling results, we performed transcription run-on assays by monitoring BrUTP incorporation in two-cell embryos as a measure 
A

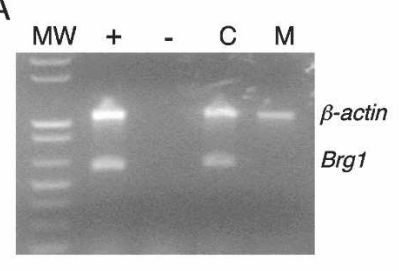

B
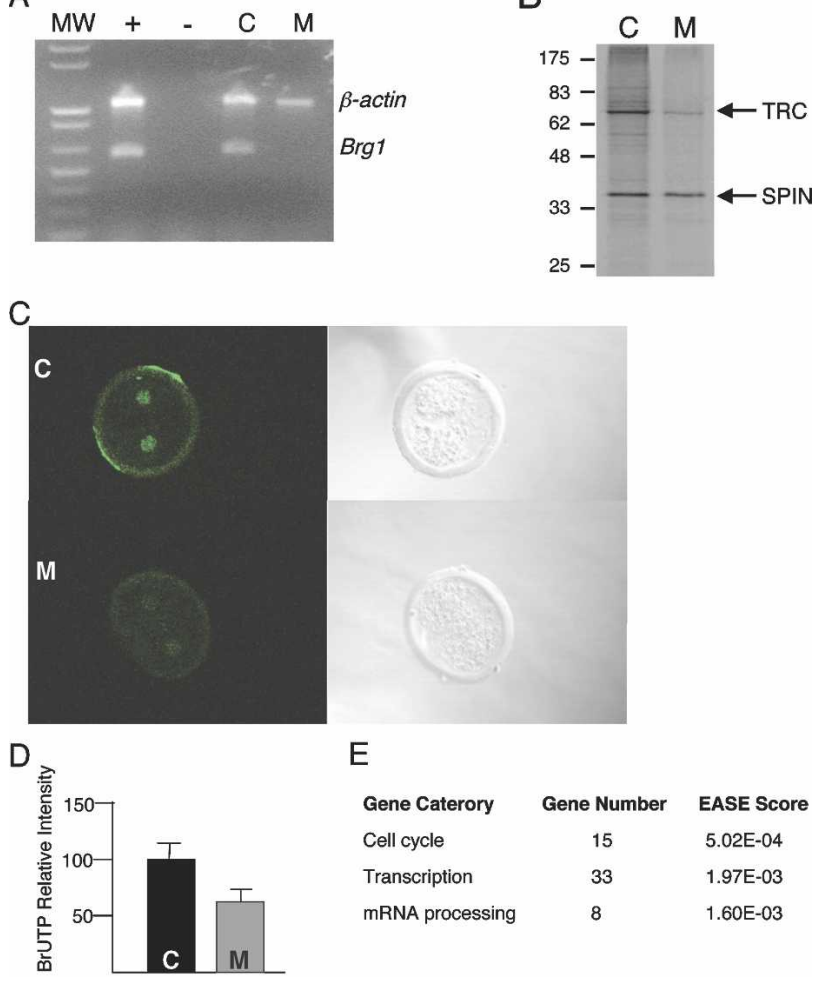

Figure 3. Reduced gene expression in $B r g 1^{\text {Zp3-Cre }}$ maternally depleted embryos. (A) Image of ethidium bromide-stained agarose gel containing $\beta$-actin (1020 bp) and Brg1 (585 bp) RT-PCR products. (MW) One-kilobase ladder molecular-weight standard; $(+)$ positive control consisting of wild-type neonatal tissues; (-) negative control consisting of wild-type neonatal tissues except reverse transcriptase was omitted from RT reaction; (C) two-cell embryos from wild-type control female $(n=15)$; (M) maternally depleted two-cell embryos $(n=15)$. (B) ${ }^{35}$ S-methionine metabolic labeling of a pool of six control (C) and six maternally depleted (M) two-cell embryos. Shown is a representative autoradiograph of a polyacrylamide gel with molecular weights (in kilodaltons) indicated at the left and the TRC and SPIN proteins indicated at the right. $(C)$ BrUTP incorporation detected by IF as a measure of genome-wide transcription. Representative confocal images of control $(\mathrm{C}, t o p)$ and maternally depleted (M, bottom) two-cell embryos are shown. (Right panels) DIC images are also shown. (D) Quantification of BrUTP incorporation data. Relative intensity of control (C) and maternally depleted $(\mathrm{M})$ embryos. (E) EASE analysis of selected biological processes.

of overall transcriptional activity. BrUTP incorporation in maternally depleted embryos was reduced by $\sim 35 \%$ compared with control embryos (Fig. 3C,D).

The list of down-regulated genes was subjected to Expression Analysis Systematic Explorer (EASE) analysis. EASE facilitates interpreting gene lists derived from microarray experiments by providing statistical methods (reported as an EASE score) for discovering biological themes within gene lists. EASE unmasks biological themes by identifying functional gene categories that are overrepresented (Hosack et al. 2003). Overrepresentation does not refer to the abundance of gene expression but rather describes a class of functionally similar genes that are enriched in a data set relative to a normal distribution of all genes assayed (Zeng et al. 2004).

EASE analysis revealed that genes involved in transcription and RNA processing as well as cell cycle regulation were preferentially overrepresented (Fig. 3E; for gene list, see Supplementary Table S2). This finding is provocative given the results of a previous study indicating genes of similar function were preferentially expressed during ZGA (Zeng et al. 2004).

\section{A direct requirement for maternal Brg1 gene product in the embryo}

The cleavage-stage arrest could be a consequence of misexpression of Brg1-regulated genes during oocyte growth and not reflect a direct role for BRG1 in ZGA per se. However, it is unlikely deficiencies in oocyte gene expression patterns contribute significantly to the developmental arrest observed at the two-cell stage. In support of this notion, microinjection of wild-type zygotes with Brg1 double-stranded RNA (dsRNA) resulted in $~ 50 \%$ of them arresting at the two- to four-cell stage (Fig. 4A). Cleavage-stage development was unaffected in zygotes injected with either GFP dsRNA or water as controls (Fig. 4A). In addition, we noted a substantial reduction in BRG1 protein levels treated with Brg1 dsRNA compared with GFP dsRNA (Fig. 4B). Thus, depletion of maternal BRG1 after oocyte development is complete phenocopied the $\operatorname{Brg} 1^{\text {Zp3-Cre }}$ oocyte-specific mutation.

\section{Normal and aberrant covalent histone modifications}

Considering that SWI/SNF-related complexes and HATs are recruited to promoters in a coordinated manner (Narlikar et al. 2002), a logical function for BRG1 in ZGA is to regulate chromatin structure and, in particular, histone modifications. To investigate a potential link between SWI/SNF-related complexes and HATs during ZGA, we tested histone acetylation levels in Brg1 $1^{\text {Zp3-Cre }}$ embryos. Pan-acetyl histone 4 (H4) levels, measured by IF, showed no significant difference between maternally depleted and control two-cell embryos (Fig. 5). Some acetylated residues, including histone 4 Lys 8 (H4K8), H4K12, and H4K16, are inversely correlated with transcription (Kurdistani et al. 2004). Therefore, it remained possible that overall acetylation levels were unchanged due to a decrease in stimulatory marks balanced with an increase in inhibitory marks. To test this hypothesis, we analyzed the levels of acetyl H3K9 as it is a specific stimulatory mark (Kurdistani et al. 2004). However, similar to the pan-acetyl $\mathrm{H} 4$ results, this modification was also unchanged (Fig. 5). These findings suggest that BRG1 and SWI/SNF-related complexes do not act upstream of histone acetylation in the two-cell embryo.

The above experiments did not rule out a role for BRG1 and SWI/SNF regulating another covalent histone modification tightly correlated with transcriptional activity, dimethyl H3K4 (Bernstein et al. 2002; Schneider 
A

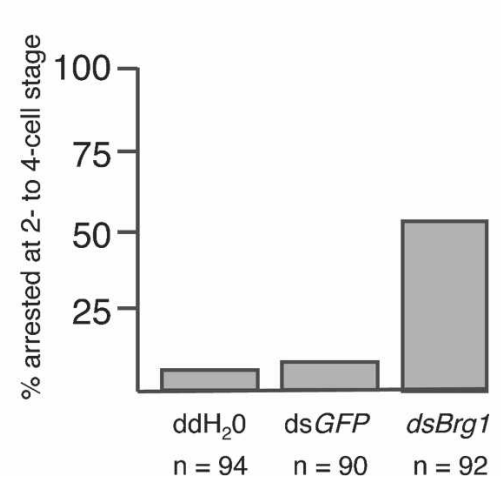

et al. 2004). Interestingly, dimethyl H3K4 levels in maternally depleted embryos were significantly reduced relative to controls (Fig. 5). Quantification of mean fluorescent activity in optical slices captured by confocal microscopy revealed that dimethyl H3K4 levels were reduced to $\sim 61 \%$ of normal in mutants (Fig. 5).

Treating maternally depleted embryos with trichostatin A (TSA), a histone deacetylase (HDAC) inhibitor, from the one- to two-cell stage significantly increased histone acetylation, dimethyl H3K4 levels, and transcription (detected by BrUTP incorporation) but did not overcome the two- to four-cell arrest (data not shown). This result was anticipated because TSA interferes with a chromatin-mediated transcriptionally repressive state superimposed upon ZGA that silences numerous genes transiently expressed during the two-cell stage. Accordingly, TSA also blocks the development of wild-type embryos beyond the two- to four-cell stage (Ma et al. 2001).

\section{Discussion}

Results described here demonstrate that Brg1 is a new member of a small but growing list of mammalian maternal-effect genes. The basis for this conclusion is threefold: (1) A Brg1 oocyte-specific mutation has no apparent effect on oocyte development, ovulation, or fertilization, but results in a developmental arrest at the two-cell stage. (2) Depletion of BRG1 subsequent to normal oocyte development phenocopies the oocyte-specific mutation. (3) Maternal BRG1 is required to successfully reprogram gene expression patterns during the two-cell stage, and failure to reprogram the zygotic genome is linked to decreased H3K4 methylation. Thus, maternal BRG1 has a decisive embryonic function following oocyte development.

Genetic screens in Drosophila have identified numerous maternal-effect genes (Perrimon et al. 1989; Schupbach and Wieschaus 1989; Bellotto et al. 2002), and molecular characterization of the maternal gene products support the notion that embryogenesis begins during oogenesis (Wolpert et al. 2002). The difficulty in conduct- ing similar mutagenesis screens in mammals has made identifying maternal-effect genes far more difficult. Nevertheless, several maternal-effect genes have been identified in mice: Mater (maternal antigen that embryos require) (Tong et al. 2000), Hsf1 (heat-shock factor 1) (Christians et al. 2000), Dnmt1o (DNA methyltransferase 1, oocyte isoform) (Howell et al. 2001), Npm2 (nucleoplasmin 2) (Burns et al. 2003; De La Fuente et al. 2004), Stella (Payer et al. 2003), Zar1 (zygotic arrest 1) (Wu et al. 2003), E-cadherin (de Vries et al. 2004), Pms2 (Gurtu et al. 2002), Ezh2 (enhancer of zeste 2) (Erhardt

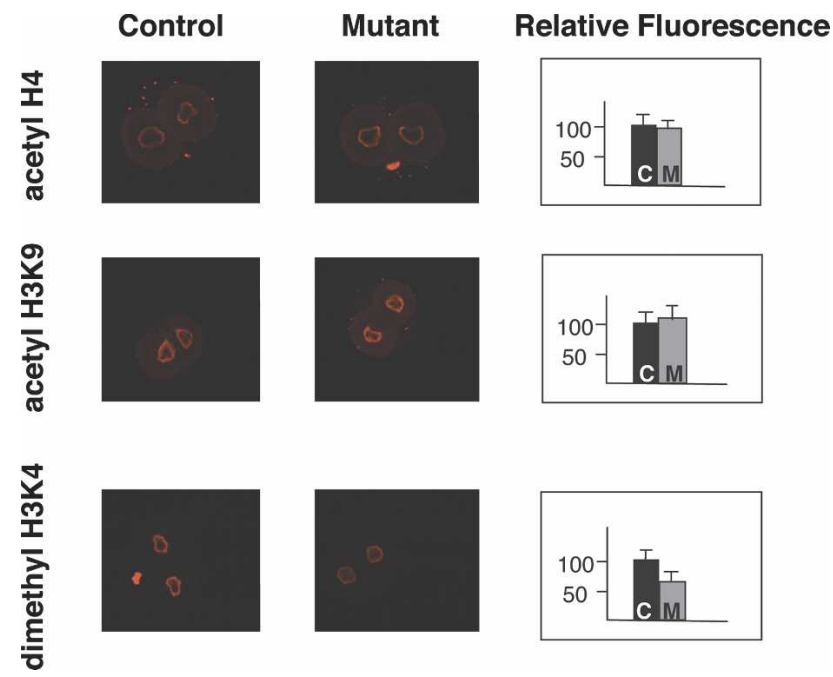

Figure 5. Normal and aberrant covalent histone modifications. Representative confocal images detecting covalent histone modifications by IF in control (genotype of dam: floxed/floxed, no transgene) and maternally depleted (Mutant) embryos. Antipan-acetyl-H4 (top row), anti-acetyl-H3K9 (middle row), and anti-dimethyl-H3K4 (bottom row) primary antibodies were utilized. Signal is excluded from nucleoli (dark spots in center). The small, bright spots corresponding to neither nucleus in the top right and bottom left panels are polar bodies. Quantification of the IF data in control (C) and maternally depleted (M) embryos is shown furthest to the right under Relative Fluorescence heading. 
et al. 2003), Dnmt3a (DNA methyltransferase 3A) (Kaneda et al. 2004), and mHR6A (RAD6-related) (Roest et al. 2004).

Apart from Brg1, E-cadherin, Pms2, Ezh2, Dnmt3a, and $m H R 6 A$, all of these maternal-effect genes are expressed exclusively in oocytes. In addition, only Mater and mHR6A mutants confer the same phenotype (i.e., two-cell arrest) as BRG1 maternally depleted embryos. The other mutants arrest primarily at the one-cell stage (Npm2, Stella, Zar1, Hsf1), during later stages of preimplantation (Stella, Pms2), or during post-implantation (Dnmt3a, Dnmt1o) development; exhibit a postnatal phenotype (Ezh2); or appear normal because of rescue from the wild-type paternal allele (E-cadherin). Moreover, the underlying molecular basis for the developmental arrest of these various mutants is poorly defined. For example, although Mater-deficient embryos arrest at the two-cell stage and display reduced expression of the TRC, the molecular mechanism underlying the phenotype has not been elucidated (Tong et al. 2004). Similarly, $m H R 6 A$ encodes a RAD6-like protein predicted to have ubiquitin-conjugating activity, but methylation of H3K4 was unaffected in mutants and transcription was not analyzed (Roest et al. 2004).

In contrast to these other maternal-effect genes, results reported here point to a plausible molecular mechanism that, when disrupted, gives rise to embryonic arrest at the two-cell stage. ZGA entails a dramatic reprogramming of gene expression that must be faithfully executed in order for development to proceed. Whereas ZGA was previously thought to be relatively promiscuous due to the extensive chromatin remodeling, results of microarray experiments demonstrate that genes involved in transcription, RNA processing, and cell cycle regulation are preferentially expressed (Zeng et al. 2004). What is of particular interest is that expression of a restricted subset of genes involved in these processes is preferentially reduced in BRG1 maternally depleted two-cell embryos. This failure to reprogram correctly likely underlies the observed two-cell arrest.

The lack of functional compensation of brahma protein (BRM), which is also expressed in oocytes and is $75 \%$ identical to BRG1, is surprising. Maternal BRM might have been expected to prevent cleavage-stage arrest until after it is degraded at the four-cell stage (LeGouy et al. 1998). Nevertheless, BRM may be compensating to prevent a block in oocyte development. Evidence to support such a compensatory function comes from Drosophila, where perturbing the sole brahma gene in the oocyte blocks oogenesis (Brizuela et al. 1994).

ZGA, by definition, must be initiated by maternally derived proteins and/or mRNAs. The identity of such maternally derived factors essential for ZGA, however, has alluded identification until recently. Recruitment of maternal cyclin A2 mRNA, in collaboration with CDK2, appears to be a critical event because genome activation is inhibited in the zygote when maternal cyclin A2 mRNA is targeted by an small interfering RNA (siRNA) (Hara et al. 2005). Moreover, microinjection of recombinant cyclin A2-CDK2 protein increases transcriptional activity (Hara et al. 2005). Maternally derived BRG1 also appears to be a critical component in the central process of genome activation and, as such, is the first maternal factor linked with expression of specific genes during ZGA. Because the oocyte-specific mutation and Brg1 dsRNA perturb zygotic Brg1 expression, lack of zygotic BRG1 may also contribute to the decreased transcriptional state and developmental arrest. Our finding of decreased dimethyl H3K4 (a mark for transcriptionally active chromatin) in BRG1-depleted embryos provides a framework for understanding the molecular mechanism of ZGA.

We propose a model outlining the relationship between maternally derived SWI/SNF-related complexes, histone acetylation, and transcription during ZGA (Fig. 6). The finding that $\mathrm{H} 4$ and H3K9 acetylation levels are normal in BRG1 maternally depleted embryos suggests SWI/SNF-related complexes act downstream of or in parallel to HATs. In support of BRG1 "reading" acetylated histones, ChIP experiments have shown that transcription factors can directly recruit HATs to promoters of downstream target genes, and this, in turn, creates docking sites for the BRG1 bromodomain and facilitates binding of SWI/SNF-related complexes (Jacobson et al. 2000; Agalioti et al. 2002; Narlikar et al. 2002; Yang

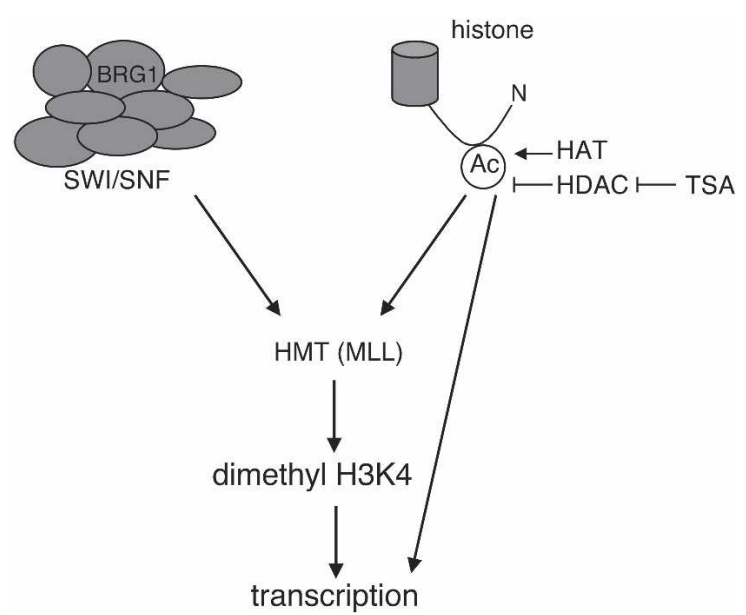

Figure 6. A model depicting the relationship of SWI/SNF-related complexes and covalent histone modifications during ZGA. Maternally derived SWI/SNF-related complexes (left) and histone acetylation (right) converge to stimulate MLL. MLL methylates $\mathrm{H} 3 \mathrm{~K} 4$, which, in turn, results in transcription. In Brg $1^{\text {Zp3-Cre }}$ maternally depleted embryos, dimethyl H3K4 and transcription are reduced but not abolished, because the histone acetylation input is intact and other chromatin remodeling complexes might compensate. For the same reason, TSA treatment of maternally depleted embryos increases histone acetylation and restores dimethyl H3K4 to levels of untreated controls and transcription to higher than normal levels nearly equal to TSA-treated controls. It is also likely that histone acetylation stimulates transcription in a dimethyl H3K4-independent manner (line from Ac to transcription). (Ac) Acetyl group on $\mathrm{N}$ terminal tail of a core histone; (HAT) histone acetyltransferase; (HDAC) histone deacetylase; (TSA) trichostatin $\mathrm{A}_{\text {; }}$ (HMT) histone methyltransferase; (MLL) mixed lineage leukemia. 
2004). Both BRG1-containing SWI/SNF complexes and acetylation of core histones influence H3K4 methylation patterns in the two-cell embryo. This conclusion is based on the findings that BRG1 maternally depleted embryos have reduced dimethyl H3K4 and increasing histone acetylation levels in control or BRG1-depleted embryos (via TSA treatment) increases dimethyl H3K4. Both of these epigenetic mechanisms must influence dimethyl H3K4 indirectly because neither one has methyltransferase activity. Based on several lines of evidence, we speculate that both SWI/SNF-related complexes and histone acetylation affect mixed-lineage leukemia (MLL) to increase dimethyl H3K4 during ZGA. First, MLL is a histone methyltransferase that specifically methylates $\mathrm{H} 3 \mathrm{~K} 4$ and is associated with transcriptional activity (Milne et al. 2002; Nakamura et al. 2002). Second, SWI/ SNF-related complexes genetically and physically interact will MLL (Dingwall et al. 1995; Rozenblatt-Rosen et al. 1998; Milne et al. 2002; Nakamura et al. 2002). Third, $\mathrm{H} 3$ acetylation stimulates MLL methyltransferase activity (Milne et al. 2002). Finally, an Mll truncation mutation, which may have dominant-negative activity by interfering with wild-type MLL protein in the oocyte, confers two-cell arrest (Ayton et al. 2001). The mutant MLL protein is predicted to lack the catalytic SET domain and could compete with wild-type MLL protein for entry into functional high-molecular-mass complexes. TSA treatment of BRG1 maternally depleted embryos has a stronger effect on acetylation and transcription than dimethyl H3K4 levels, and this result suggests that acetylation can also stimulate transcription in a dimethyl H3K4 independent manner.

Identifying additional factors involved in ZGA will provide further insight into how the genome is transformed from a transcriptionally quiescent state at fertilization to one that is robustly transcribed shortly thereafter. Consequently, we should gain a better understanding of how the genome is reprogrammed such that the restricted developmental potential of the highly differentiated egg and sperm pronuclei is restored to the totipotent state of the cleavage-stage embryo. Such knowledge may have implications in the field of cloning (i.e., somatic cell nuclear transfer) because a similar reprogramming event must occur following introduction of a somatic nucleus into a recipient egg. In this regard, it is noteworthy that BRG1 and ISWI chromatin remodeling complexes are required to reprogram somatic nuclei of differentiated cells (Kikyo et al. 2000; Hansis et al. 2004). These data, together with the work presented here, implicate BRG1 and chromatin remodeling as central players in the process or reprogramming the mammalian genome.

\section{Materials and methods}

\section{Genotyping of mice}

Mice were maintained on a mixed genetic background and genotyped for Brg1 1ull, Brg1 $1^{\text {floxed }}$, and the Zp3-Cre transgene as already described (Lewandoski et al. 1997; Sumi-Ichinose et al. 1997; Bultman et al. 2000).

\section{Histology}

Ovaries were dissected, fixed in 4\% paraformaldehyde, and processed for the production of paraffin sections. Sections $(5-8 \mu \mathrm{m})$ were stained with $\mathrm{H} \& \mathrm{E}$.

\section{Embryo culture}

According to standard procedures (Hogan et al. 1994), fertilized eggs or two-cell embryos were flushed out of oviducts and cultured in KSOM supplemented with amino acids (Specialty Media) in a $37^{\circ} \mathrm{C}$ incubator containing $5 \% \mathrm{CO}_{2}$.

\section{${ }^{35}$ S-methionine metabolic labeling}

Two-cell embryos were metabolically radiolabeled with ${ }^{35} \mathrm{~S}$ methionine, and the radiolabeled proteins were resolved by SDS-PAGE and detected by autoradiography as previously described (Conover et al. 1991).

\section{RNA extraction, labeling, and hybridization}

Total RNA was extracted from 20 two-cell embryos, amplified, labeled, and fragmented as previously described (Pan et al. 2005). Each embryo sample was collected from a single mouse, and four separate samples were analyzed for each group. The yield of biotinylated cRNA for each replicate was 45-70 $\mu$, and the RNA samples were submitted to the Penn Microarray Facility and hybridized to MOE430 version 2 GeneChips (Affymetrix), which contain $\sim 39,000$ transcripts that cover most of the mouse genome. Quality-control parameters (e.g., percentage present, $3^{\prime}: 5^{\prime}$ ratio) are found in Supplementary Table S3 and indicate that the microarray data generated were of high quality.

\section{Microarray data analyses}

Microarray Analysis Suite 5.0 (MAS, Affymetrix) was used to quantify microarray signals with default analysis parameters and global scaling to target $\mathrm{MEAN}=200$. GeneChip tabular data are available at the Gene Expression Omnibus repository (http://www.ncbi.nlm.nih.gov/geo). The MAS metrics output was loaded into GeneSpring version 7.2 (Silicon Genetics) with per-chip normalization to the 50th percentile and per-gene normalization to the median. Condition tree clustering was used to identify relationships among the global gene expression levels of samples. To minimize false positives, only the genes called as "Present" in at least three out of four replicates for each treatment group were used for Statistical Analysis of Microarrays (SAM). Because four biological replicates provided sufficient statistical power and confidence levels to detect a 1.4-fold difference in RNA abundance (Zeng et al. 2004), genes with significant differences of 1.4-fold or greater between conditions were identified at a $5 \%$ false discovery rate using SAM. The resulting gene lists were then imported into EASE (version 2.0) to analyze the gene ontology for overrepresentation (Hosack et al. 2003). The EASE score was calculated for likelihood of overrepresentation of annotation classes and only selected biological processes with an EASE score $<5 \%$ are shown. Note that on the Affymetrix Genechip used, each probe set represents one gene but many Unigenes are represented more than once by different probe sets.

\section{$R T-P C R$}

RT-PCR conditions for Brg1 have already been described (Bultman et al. 2000). The same conditions were utilized for $\beta$-actin 
except the primer sequences (forward, $5^{\prime}$-CAAGGTGTGATGG TGGGAAT-3'; reverse, 5'-GGTGTAAAACGCAGCTCAGT-3').

\section{RNAi}

RNAi was performed as described (Svoboda et al. 2000; Wianny and Zernicka-Goetz 2000). The Brg1 dsRNA corresponded to nucleotides 2142-2734 of the cDNA sequence (Sumi-Ichinose et al. 1997). The top (i.e., coding) strand of the dsRNA begins with TCTGAGGTGGACGCCCGACACATTATTGAG and ends with CACTGCAAGTTGACGCAGGTCCTTAACACA.

\section{IF and BrUTP assays}

For BRG1 IF, unfertilized eggs were fixed in chilled methanol, washed three times in PBS, and blocked in 10\% normal goat serum in PBS. The primary antibody was a mouse monoclonal (Santa Cruz Biotechnology) used at a 1:50 dilution. Samples were washed three times in PBS, and a goat-anti-mouse secondary antibody conjugated to Alexa 594 (Molecular Probes) was used at a 1:300 dilution. Following three additional washes in PBS, samples were transferred to microdrops of Vectashield mounting media (Vector Laboratories) in adhesive imaging chambers (Schleicher \& Schuell) sandwiched between glass coverslips.

For the analysis of covalent histone modifications and BrUTP incorporation by IF, one-cell embryos were recovered from ampullae at E0.5 and cultured in KSOM (Specialty Media) in the presence or absence of $50 \mathrm{nM}$ TSA (BIOMOL International) overnight to the two-cell stage. For analysis of covalent histone modifications, IF was performed as previously described (Sarmento et al. 2004). Primary antibodies were rabbit polyclonals and diluted according to the manufacturer's (Upstate) recommendations. The secondary was a goat-anti-rabbit conjugated to Alexa 594 (Molecular Probes) used at a 1:200 dilution.

BrUTP incorporation assays were performed as previously described (Aoki et al. 1997). Briefly, the plasma membranes of two-cell embryos were permeabilized for 1-2 min with $0.05 \%$ Triton X-100 in physiological buffer (PB) that consisted of 100 $\mathrm{mM}$ potassium acetate, $30 \mathrm{mM} \mathrm{KCl}, 1 \mathrm{mM} \mathrm{MgCl}, 10 \mathrm{mM}$ $\mathrm{Na}_{2} \mathrm{HPO}_{4}, 1 \mathrm{mM} \mathrm{ATP}, 1 \mathrm{mM} \mathrm{DTT}, 0.2 \mathrm{mM} \mathrm{PMSF}$, and $50 \mathrm{U} / \mathrm{mL}$ of RNasin. Embryos were subsequently washed three times in $\mathrm{PB}$ and transferred to transcription buffer consisting of $100 \mathrm{mM}$ potassium acetate, $30 \mathrm{mM} \mathrm{KCl}, 2 \mathrm{mM} \mathrm{MgCl}_{2}, 10 \mathrm{mM}$ $\mathrm{Na}_{2} \mathrm{HPO}_{4}, 2 \mathrm{mM}$ ATP, and $0.4 \mathrm{mM}$ each of GTP, CTP, and BrUTP (Molecular Probes). Transcription reactions proceeded for $10 \mathrm{~min}$ at $33^{\circ} \mathrm{C}$, and the nuclear membranes were subsequently permeabilized for $3 \mathrm{~min}$ in $\mathrm{PB}$ containing $0.2 \%$ Triton $\mathrm{X}-100$. Embryos were then washed in $\mathrm{PB}$ three times and fixed overnight in $4 \%$ paraformaldehyde at $4^{\circ} \mathrm{C}$. Embryos were washed and blocked through five changes of PBS containing $3 \mathrm{mg} / \mathrm{mL}$ BSA (PBS/BSA) and incubated for $45 \mathrm{~min}$ with a mouse monoclonal antibody raised against BrdU (BoehringerMannheim) diluted to $2 \mu \mathrm{g} / \mathrm{mL}$ in PBS/BSA. Embryos were washed in PBS/BSA, incubated in a goat-anti-mouse secondary antibody conjugated to FITC or Alexa 594 (Molecular Probes) at a 1:300 dilution, washed again in PBS/BSA, and mounted in Vectashield medium as described above.

\section{Confocal microscopy and quantification of IF}

IF was detected using a LSMJ confocal instrument (Carl Zeiss). Focal planes with the greatest signal intensity were identified by focusing through the entire egg or two-cell embryo, and composite images representing the mean of four optical slices from these most intense focal planes were saved. Nucleoli were evi- dent as a dark center surrounded by a ring of fluorescence in images of covalent histone modifications. The nucleoli served as landmarks to confirm that similar focal planes were being compared in controls and mutants. Quantification was performed using NIH Image J software (National Institutes of Health). Briefly, nuclear signal was outlined and mean fluorescence intensity was measured. This same encircled region was dragged to the cytoplasm of the same cell, and background fluorescence was measured. Specific signal was calculated by dividing nuclear values by cytoplasmic values. The mean of untreated controls was set as $100 \%$ relative fluorescent intensity. Treated controls as well as untreated and treated mutants were expressed relative to untreated controls. Standard deviations were calculated and are represented by error bars.

\section{Acknowledgments}

We thank J. Brennan, S. Chamberlin, and N. Montgomery for helpful discussions and their comments on this manuscript. We also acknowledge G. Martin and B. Knowles for Zp3-Cre mice, P. Chambon and D. Metzger for Brg1 floxed mice, R. Thresher and $\mathrm{K}$. Kluckman at the UNC animal models core for microinjection of dsRNAs, and B. Bagnell and V. Madden at the UNC Microscopy Services Laboratory for assistance with confocal imaging. This work was supported, in part, by grants from the NIH (HD22681 to R.M.S. and HD36655 to T.M.).

\section{References}

Agalioti, T., Chen, G., and Thanos, D. 2002. Deciphering the transcriptional histone acetylation code for a human gene. Cell 111: 381-392.

Aoki, F., Worrad, D.M., and Schultz, R.M. 1997. Regulation of transcriptional activity during the first and second cell cycles in the preimplantation mouse embryo. Dev. Biol. 181: 296-307.

Ayton, P., Sneddon, S.F., Palmer, D.B., Rosewell, I.R., Owen, M.J., Young, B., Presley, R., and Subramanian, V. 2001. Truncation of the Mll gene in exon 5 by gene targeting leads to early preimplantation lethality of homozygous embryos. Genesis 30: 201-212.

Bazett-Jones, D.P., Cote, J., Landel, C.C., Peterson, C.L., and Workman, J.L. 1999. The SWI/SNF complex creates loop domains in DNA and polynucleosome arrays and can disrupt DNA-histone contacts within these domains. Mol. Cell. Biol. 19: 1470-1478.

Bellotto, M., Bopp, D., Senti, K.A., Burke, R., Deak, P., Maroy, P., Dickson, B., Basler, K., and Hafen, E. 2002. Maternaleffect loci involved in Drosophila oogenesis and embryogenesis: P element-induced mutations on the third chromosome. Int. J. Dev. Biol. 46: 149-157.

Bernstein, B.E., Humphrey, E.L., Erlich, R.L., Schneider, R., Bouman, P., Liu, J.S., Kouzarides, T., and Schreiber, S.L. 2002. Methylation of histone H3 Lys 4 in coding regions of active genes. Proc. Natl. Acad. Sci. 99: 8695-8700.

Bolton, V.N., Oades, P.J., and Johnson, M.H. 1984. The relationship between cleavage, DNA replication, and gene expression in the mouse two-cell embryo. J. Embryol. Exp. Morphol. 79: 139-163.

Brizuela, B.J., Elfring, L., Ballard, J., Tamkun, J.W., and Kennison, J.A. 1994. Genetic analysis of the brahma gene of Drosophila melanogaster and polytene chromosome subdivisions 72AB. Genetics 137: 803-813.

Bultman, S., Gebuhr, T., Yee, D., La Mantia, C., Nicholson, J., Gilliam, A., Randazzo, F., Metzger, D., Chambon, P., Crab- 
tree, G., et al. 2000. A Brgl null mutation in the mouse reveals functional differences among mammalian SWI/SNF complexes. Mol. Cell 6: 1287-1295.

Bultman, S.J., Gebuhr, T.C., and Magnuson, T. 2005. A Brg1 mutation that uncouples ATPase activity from chromatin remodeling reveals an essential role for SWI/SNF-related complexes in $\beta$-globin expression and erythroid development. Genes \& Dev. 19: 2849-2861.

Burns, K.H., Viveiros, M.M., Ren, Y., Wang, P., DeMayo, F.J., Frail, D.E., Eppig, J.J., and Matzuk, M.M. 2003. Roles of NPM2 in chromatin and nucleolar organization in oocytes and embryos. Science 300: 633-636.

Christians, E., Davis, A.A., Thomas, S.D., and Benjamin, I.J. 2000. Maternal effect of Hsf1 on reproductive success. $\mathrm{Na}$ ture 407: 693-694.

Conover, J.C., Temeles, G.L., Zimmermann, J.W., Burke, B., and Schultz, R.M. 1991. Stage-specific expression of a family of proteins that are major products of zygotic gene activation in the mouse embryo. Dev. Biol. 144: 392-404.

De La Fuente, R., Viveiros, M.M., Burns, K.H., Adashi, E.Y., Matzuk, M.M., and Eppig, J.J. 2004. Major chromatin remodeling in the germinal vesicle $(\mathrm{GV})$ of mammalian oocytes is dispensable for global transcriptional silencing but required for centromeric heterochromatin function. Dev. Biol. 275: $447-458$.

de Vries, W.N., Binns, L.T., Fancher, K.S., Dean, J., Moore, R., Kemler, R., and Knowles, B.B. 2000. Expression of Cre recombinase in mouse oocytes: A means to study maternal effect genes. Genesis 26: 110-112.

de Vries, W.N., Evsikov, A.V., Haac, B.E., Fancher, K.S., Holbrook, A.E., Kemler, R., Solter, D., and Knowles, B.B. 2004. Maternal $\beta$-catenin and E-cadherin in mouse development. Development 131: 4435-4445.

Dingwall, A.K., Beek, S.J., McCallum, C.M., Tamkun, J.W., Kalpana, G.V., Goff, S.P., and Scott, M.P. 1995. The Drosophila snrl and brm proteins are related to yeast SWI/SNF proteins and are components of a large protein complex. Mol. Biol. Cell 6: 777-791.

Erhardt, S., Su, I.H., Schneider, R., Barton, S., Bannister, A.J., Perez-Burgos, L., Jenuwein, T., Kouzarides, T., Tarakhovsky, A., and Surani, M.A. 2003. Consequences of the depletion of zygotic and embryonic enhancer of zeste 2 during preimplantation mouse development. Development 130: 4235-4248.

Flach, G., Johnson, M.H., Braude, P.R., Taylor, R.A., and Bolton, V.N. 1982. The transition from maternal to embryonic control in the two-cell mouse embryo. EMBO J. 1: 681-686.

Gebuhr, T.C., Kovalev, G.I., Bultman, S., Godfrey, V., Su, L., and Magnuson, T. 2003. The role of Brg1, a catalytic subunit of mammalian chromatin-remodeling complexes, in $\mathrm{T}$ cell development. J. Exp. Med. 198: 1937-1949.

Guidi, C.J., Sands, A.T., Zambrowicz, B.P., Turner, T.K., Demers, D.A., Webster, W., Smith, T.W., Imbalzano, A.N., and Jones, S.N. 2001. Disruption of Inil leads to peri-implantation lethality and tumorigenesis in mice. Mol. Cell. Biol. 21: 3598-3603.

Gurtu, V.E., Verma, S., Grossmann, A.H., Liskay, R.M., Skarnes, W.C., and Baker, S.M. 2002. Maternal effect for DNA mismatch repair in the mouse. Genetics 160: 271-277.

Hansis, C., Barreto, G., Maltry, N., and Niehrs, C. 2004. Nuclear reprogramming of human somatic cells by Xenopus egg extract requires BRG1. Curr. Biol. 14: 1475-1480.

Hara, K.T., Oda, S., Naito, K., Nagata, M., Schultz, R.M., and Aoki, F. 2005. Cyclin A2-CDK2 regulates embryonic gene activation in 1-cell mouse embryos. Dev. Biol. 286: 102-113.

Hogan, B., Beddington, R., Costantini, F., and Lacy, E. 1994. Manipulating the mouse embryo. Cold Spring Harbor Press,
Cold Spring Harbor, NY.

Hosack, D.A., Dennis Jr., G., Sherman, B.T., Lane, H.C., and Lempicki, R.A. 2003. Identifying biological themes within lists of genes with EASE. Genome Biol. 4: R70.

Howell, C.Y., Bestor, T.H., Ding, F., Latham, K.E., Mertineit, C., Trasler, J.M., and Chaillet, J.R. 2001. Genomic imprinting disrupted by a maternal effect mutation in the Dnmtl gene. Cell 104: 829-838.

Jacobson, R.H., Ladurner, A.G., King, D.S., and Tjian, R. 2000. Structure and function of a human TAFII250 double bromodomain module. Science 288: 1422-1425.

Kaneda, M., Okano, M., Hata, K., Sado, T., Tsujimoto, N., Li, E., and Sasaki, H. 2004. Essential role for de novo DNA methyltransferase Dnmt3a in paternal and maternal imprinting. Nature 429: 900-903.

Kanka, J. 2003. Gene expression and chromatin structure in the pre-implantation embryo. Theriogenology 59: 3-19.

Kikyo, N., Wade, P.A., Guschin, D., Ge, H., and Wolffe, A.P. 2000. Active remodeling of somatic nuclei in egg cytoplasm by the nucleosomal ATPase ISWI. Science 289: 2360-2362.

Kim, J.K., Huh, S.O., Choi, H., Lee, K.S., Shin, D., Lee, C., Nam, J.S., Kim, H., Chung, H., Lee, H.W., et al. 2001. Srg3, a mouse homolog of yeast SWI3, is essential for early embryogenesis and involved in brain development. Mol. Cell. Biol. 21: 7787-7795.

Kingston, R.E. and Narlikar, G.J. 1999. ATP-dependent remodeling and acetylation as regulators of chromatin fluidity. Genes \& Dev. 13: 2339-2352.

Klochendler-Yeivin, A., Fiette, L., Barra, J., Muchardt, C., Babinet, C., and Yaniv, M. 2000. The murine SNF5/INI1 chromatin remodeling factor is essential for embryonic development and tumor suppression. EMBO Rep. 1: 500-506.

Kurdistani, S.K., Tavazoie, S., and Grunstein, M. 2004. Mapping global histone acetylation patterns to gene expression. Cell 117: 721-733.

Latham, K.E., Solter, D., and Schultz, R.M. 1992. Acquisition of a transcriptionally permissive state during the 1-cell stage of mouse embryogenesis. Dev. Biol. 149: 457-462.

LeGouy, E., Thompson, E.M., Muchardt, C., and Renard, J.P. 1998. Differential preimplantation regulation of two mouse homologues of the yeast SWI2 protein. Dev. Dyn. 212: 38 48.

Lewandoski, M., Wassarman, K.M., and Martin, G.R. 1997. $\mathrm{Zp} 3$-cre, a transgenic mouse line for the activation or inactivation of loxP-flanked target genes specifically in the female germ line. Curr. Biol. 7: 148-151.

Lickert, H., Takeuchi, J.K., Von Both, I., Walls, J.R., McAuliffe, F., Adamson, S.L., Henkelman, R.M., Wrana, J.L., Rossant, J., and Bruneau, B.G. 2004. Baf60c is essential for function of BAF chromatin remodelling complexes in heart development. Nature 432: 107-112.

Ma, J., Svoboda, P., Schultz, R.M., and Stein, P. 2001. Regulation of zygotic gene activation in the preimplantation mouse embryo: Global activation and repression of gene expression. Biol. Reprod. 64: 1713-1721.

Milne, T.A., Briggs, S.D., Brock, H.W., Martin, M.E., Gibbs, D., Allis, C.D., and Hess, J.L. 2002. MLL targets SET domain methyltransferase activity to Hox gene promoters. Mol. Cell 10: $1107-1117$.

Mohrmann, L. and Verrijzer, C.P. 2005. Composition and functional specificity of SWI2/SNF2 class chromatin remodeling complexes. Biochim. Biophys. Acta 1681: 59-73.

Nakamura, T., Mori, T., Tada, S., Krajewski, W., Rozovskaia, T., Wassell, R., Dubois, G., Mazo, A., Croce, C.M., and Canaani, E. 2002. ALL-1 is a histone methyltransferase that assembles a supercomplex of proteins involved in transcriptional regu- 
lation. Mol. Cell 10: 1119-1128.

Narlikar, G.J., Fan, H.Y., and Kingston, R.E. 2002. Cooperation between complexes that regulate chromatin structure and transcription. Cell 108: 475-487.

Oh, B., Hwang, S.Y., Solter, D., and Knowles, B.B. 1997. Spindlin, a major maternal transcript expressed in the mouse during the transition from oocyte to embryo. Development 124: 493-503.

Olave, I., Wang, W., Xue, Y., Kuo, A., and Crabtree, G.R. 2002. Identification of a polymorphic, neuron-specific chromatin remodeling complex. Genes \& Dev. 16: 2509-2517.

Pan, H., O'Brien, M.J., Wigglesworth, K., Eppig, J.J., and Schultz, R.M. 2005. Transcript profiling during mouse oocyte development and the effect of gonadotropin priming and development in vitro. Dev. Biol. 286: 493-506.

Payer, B., Saitou, M., Barton, S.C., Thresher, R., Dixon, J.P., Zahn, D., Colledge, W.H., Carlton, M.B., Nakano, T., and Surani, M.A. 2003. Stella is a maternal effect gene required for normal early development in mice. Curr. Biol. 13: 2110-2117.

Perrimon, N., Engstrom, L., and Mahowald, A.P. 1989. Zygotic lethals with specific maternal effect phenotypes in Drosophila melanogaster. I. Loci on the X chromosome. Genetics 121: 333-352.

Peterson, C.L. and Workman, J.L. 2000. Promoter targeting and chromatin remodeling by the SWI/SNF complex. Curr. Opin. Genet. Dev. 10: 187-192.

Roberts, C.W., Galusha, S.A., McMenamin, M.E., Fletcher, C.D., and Orkin, S.H. 2000. Haploinsufficiency of Snf5 (integrase interactor 1) predisposes to malignant rhabdoid tumors in mice. Proc. Nat1. Acad. Sci. 97: 13796-13800.

Roest, H.P., Baarends, W.M., de Wit, J., van Klaveren, J.W., Wassenaar, E., Hoogerbrugge, J.W., van Cappellen, W.A., Hoeijmakers, J.H., and Grootegoed, J.A. 2004. The ubiquitin-conjugating DNA repair enzyme HR6A is a maternal factor essential for early embryonic development in mice. Mol. Cell. Biol. 24: 5485-5495.

Rozenblatt-Rosen, O., Rozovskaia, T., Burakov, D., Sedkov, Y., Tillib, S., Blechman, J., Nakamura, T., Croce, C.M., Mazo, A., and Canaani, E. 1998. The C-terminal SET domains of ALL-1 and TRITHORAX interact with the INI1 and SNR1 proteins, components of the SWI/SNF complex. Proc. Nat1. Acad. Sci. 95: 4152-4157.

Sarmento, O.F., Digilio, L.C., Wang, Y., Perlin, J., Herr, J.C., Allis, C.D., and Coonrod, S.A. 2004. Dynamic alterations of specific histone modifications during early murine development. J. Cell Sci. 117: 4449-4459.

Schneider, R., Bannister, A.J., Myers, F.A., Thorne, A.W., CraneRobinson, C., and Kouzarides, T. 2004. Histone H3 lysine 4 methylation patterns in higher eukaryotic genes. Nat. Cell Biol. 6: 73-77.

Schultz, R.M. 1993. Regulation of zygotic gene activation in the mouse. Bioessays 15: 531-538.

- 2002. The molecular foundations of the maternal to zygotic transition in the preimplantation embryo. Hum. Reprod. Update 8: 323-331.

Schultz, R.M. and Worrad, D.M. 1995. Role of chromatin structure in zygotic gene activation in the mammalian embryo. Semin. Cell Biol. 6: 201-208.

Schupbach, T. and Wieschaus, E. 1989. Female sterile mutations on the second chromosome of Drosophila melanogaster. I. Maternal effect mutations. Genetics 121: 101-117.

Smith, C.L., Horowitz-Scherer, R., Flanagan, J.F., Woodcock, C.L., and Peterson, C.L. 2003. Structural analysis of the yeast SWI/SNF chromatin remodeling complex. Nat. Struct. Biol. 10: $141-145$

Stein, P., Worrad, D.M., Belyaev, N.D., Turner, B.M., and
Schultz, R.M. 1997. Stage-dependent redistributions of acetylated histones in nuclei of the early preimplantation mouse embryo. Mol. Reprod. Dev. 47: 421-429.

Sumi-Ichinose, C., Ichinose, H., Metzger, D., and Chambon, P. 1997. SNF2 $\beta-B R G 1$ is essential for the viability of F9 murine embryonal carcinoma cells. Mol. Cell. Biol. 17: 5976-5986.

Svoboda, P., Stein, P., Hayashi, H., and Schultz, R.M. 2000. Selective reduction of dormant maternal mRNAs in mouse oocytes by RNA interference. Development 127: 4147-4156.

Telford, N.A., Watson, A.J., and Schultz, G.A. 1990. Transition from maternal to embryonic control in early mammalian development: A comparison of several species. Mol. Reprod. Dev. 26: 90-100.

Thompson, E.M., Legouy, E., and Renard, J.P. 1998. Mouse embryos do not wait for the MBT: Chromatin and RNA polymerase remodeling in genome activation at the onset of development. Dev. Genet. 22: 31-42.

Tong, Z.B., Gold, L., Pfeifer, K.E., Dorward, H., Lee, E., Bondy, C.A., Dean, J., and Nelson, L.M. 2000. Mater, a maternal effect gene required for early embryonic development in mice. Nat. Genet. 26: 267-268.

Tong, Z.B., Gold, L., De Pol, A., Vanevski, K., Dorward, H., Sena, P., Palumbo, C., Bondy, C.A., and Nelson, L.M. 2004. Developmental expression and subcellular localization of mouse MATER, an oocyte-specific protein essential for early development. Endocrinology 145: 1427-1434.

Vernet, M., Bonnerot, C., Briand, P., and Nicolas, J.F. 1992. Changes in permissiveness for the expression of microinjected DNA during the first cleavages of mouse embryos. Mech. Dev. 36: 129-139.

Wang, W., Cote, J., Xue, Y., Zhou, S., Khavari, P.A., Biggar, S.R., Muchardt, C., Kalpana, G.V., Goff, S.P., Yaniv, M., et al. 1996a. Purification and biochemical heterogeneity of the mammalian SWI-SNF complex. EMBO J. 15: 5370-5382.

Wang, W., Xue, Y., Zhou, S., Kuo, A., Cairns, B.R., and Crabtree, G.R. 1996b. Diversity and specialization of mammalian SWI/SNF complexes. Genes \& Dev. 10: 2117-2130.

Wang, Z., Zhai, W., Richardson, J.A., Olson, E.N., Meneses, J.J., Firpo, M.T., Kang, C., Skarnes, W.C., and Tjian, R. 2004. Polybromo protein BAF180 functions in mammalian cardiac chamber maturation. Genes \& Dev. 18: 3106-3116.

Whitehouse, I., Flaus, A., Cairns, B.R., White, M.F., Workman, J.L., and Owen-Hughes, T. 1999. Nucleosome mobilization catalysed by the yeast SWI/SNF complex. Nature 400: 784-787.

Wianny, F. and Zernicka-Goetz, M. 2000. Specific interference with gene function by double-stranded RNA in early mouse development. Nat. Cell Biol. 2: 70-75.

Wolpert, L., Beddington, R., Jessell, T., Lawrence, P., Meyerowitz, E., and Smith, J. 2002. Principles of development. Oxford University Press, New York.

Worrad, D.M., Turner, B.M., and Schultz, R.M. 1995. Temporally restricted spatial localization of acetylated isoforms of histone H4 and RNA polymerase II in the 2cell mouse embryo. Development 121: 2949-2959.

Wu, X., Viveiros, M.M., Eppig, J.J., Bai, Y., Fitzpatrick, S.L., and Matzuk, M.M. 2003. Zygote arrest 1 (Zar1) is a novel maternal-effect gene critical for the oocyte-to-embryo transition. Nat. Genet. 33: 187-191.

Yang, X.J. 2004. Lysine acetylation and the bromodomain: A new partnership for signaling. Bioessays 26: 1076-1087.

Zeng, F. and Schultz, R.M. 2005. RNA transcript profiling during zygotic gene activation in the preimplantation mouse embryo. Dev. Biol. 283: 40-57.

Zeng, F., Baldwin, D.A., and Schultz, R.M. 2004. Transcript profiling during preimplantation mouse development. Dev. Biol. 272: 483-496. 


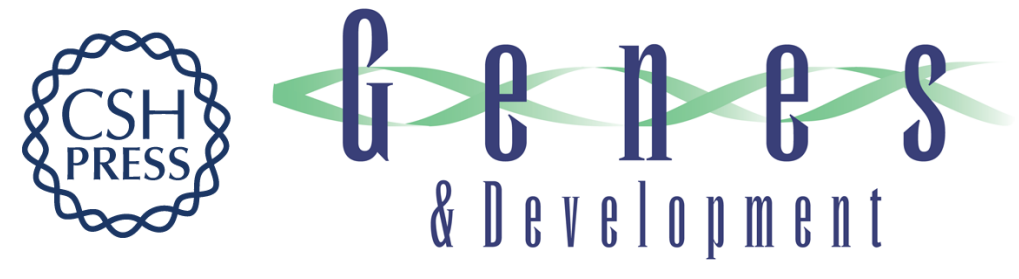

\section{Maternal BRG1 regulates zygotic genome activation in the mouse}

Scott J. Bultman, Thomas C. Gebuhr, Hua Pan, et al.

Genes Dev. 2006, 20:

Access the most recent version at doi:10.1101/gad.1435106

Supplemental
Material http://genesdev.cshlp.org/content/suppl/2006/06/09/20.13.1744.DC1

References This article cites 77 articles, 29 of which can be accessed free at: http://genesdev.cshlp.org/content/20/13/1744.full.html\#ref-list-1

License

Email Alerting Receive free email alerts when new articles cite this article - sign up in the box at the top Service right corner of the article or click here.

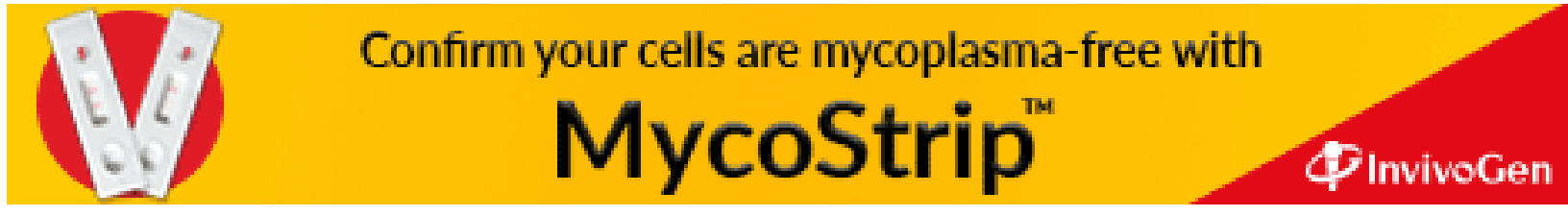

